\title{
First survey for the amphibian chytrid fungus Batrachochytrium dendrobatidis in Connecticut (USA) finds widespread prevalence
}

\author{
Kathryn L. Richards-Hrdlicka ${ }^{1, *}$, Jonathan L. Richardson ${ }^{2}$, Leon Mohabir ${ }^{3}$ \\ ${ }^{1}$ School of Forestry and Environmental Studies, Yale University, New Haven, Connecticut 06511, USA \\ ${ }^{2}$ Department of Ecology and Evolutionary Biology, University of Connecticut, Storrs, Connecticut 06269, USA \\ ${ }^{3}$ Quinnipiac University, Hamden, Connecticut 06518, USA
}

\begin{abstract}
The amphibian chytrid fungus Batrachochytrium dendrobatidis $(B d)$ is an emerging infectious fungal pathogen of amphibians and is linked to global population declines. Until now, there has only been 1 survey for the fungus in the northeastern USA, which focused primarily on northern New England. We tested for Bd in a large number of samples (916 individuals from 116 sites) collected throughout the state of Connecticut, representing 18 native amphibian species. In addition, 239 preserved wood frog Lithobates sylvaticus tadpoles from throughout the state were screened for the fungus. $B d$ presence was assessed in both the fresh field swabs and the preserved samples using a sensitive quantitative PCR assay. Our contemporary survey found widespread $B d$ prevalence throughout Connecticut, occurring in 14 species and in $28 \%$ of all sampled animals. No preserved $L$. sylvaticus specimens tested positive for the fungus. Two common species, bullfrogs $R$. catesbeiana and green frogs $R$. clamitans had particularly high infection rates (0.21-0.39 and $0.33-0.42$, respectively), and given their wide distribution throughout the state, we suggest they may serve as sentinels for $B d$ occurrence in this region. Further analyses found that several other factors increase the likelihood of infection, including life stage, host sex, and host family. Within sites, ponds with ranids, especially green frogs, increased the likelihood of $B d$ prevalence. By studying $B d$ in populations not facing mass declines, the results from this study are an important contribution to our understanding of how some amphibian species and populations remain infected yet exhibit no signs of chytridiomycosis even when $B d$ is widely distributed.
\end{abstract}

KEY WORDS: Frog · Toad - Salamander - Chytridiomycosis · Emerging infectious disease · New England $\cdot \mathrm{qPCR} \cdot$ Lithobates catesbeiana $\cdot$ Lithobates clamitans

\section{INTRODUCTION}

The chytridiomycete fungus Batrachochytrium dendrobatidis $(B d)$ is implicated in the global decline of amphibian populations (Berger et al. 1998, Stuart et al. 2004, Wake \& Vredenburg 2008). Identified in the late 1990s (Berger et al. 1998, Longcore et al. 1999), $B d$ has received much research attention, as many scientists are working to identify its range and what host species are susceptible to infection (e.g. Woodhams et al. 2008, Bielby et al. 2009, Gaertner et al. 2009, Murphy et al. 2009). Many of the regions and species that are the focus of extensive research efforts are those either currently undergoing declines or are species of conservation concern (e.g. Berger et al. 1998, Bosch et al. 2001, Lips et al. 2006, Voordouw et al. 2010). However, to fully understand its ecology, it is helpful to identify where $B d$ does and where it does not occur. This includes screening populations that 
are not undergoing disease-related dieoffs and not solely focusing on active decline sites.

New England is among the regions that has not been well surveyed for $B d$, perhaps because there have been no apparent dieoffs consistent with chytridiomycosis, such as those noted in Panama (Lips et al. 2006). Until now, our only understanding of the range and prevalence of $B d$ in this region of the USA comes from a single survey by Longcore et al. (2007). They sampled 86 sites between 2000 and 2002 from 5 states (New York, Vermont, New Hampshire, Maine, and Massachusetts); of these, 74 sites were located in Maine. Rhode Island and Connecticut (CT) were not surveyed. They analyzed 751 animals representing both pre- and post-metamorphic stages and 3 species of caudates and 9 anuran species. Specimens were analyzed for $B d$ via histology or microscopy of fresh tissues; no molecular tests were performed. $B d$ was not found in any caudate. Anurans with the greatest infection prevalence were the northern leopard frog Lithobates pipiens (0.26 prevalence), green frog L. clamitans (0.26), pickerel frog $L$. palustris (0.23) and the bullfrog L. catesbeiana (0.22).

To date, no data are available for $B d$ in CT. Our goal was to screen for $B d$ in as many species as possible, including species of all abundances, and from as many sites as possible. CT hosts 23 (1 is a recognized hybrid) amphibian species, of which 4 are listed as species of conservation concern in the state (Klemens 2000). Both recognized blue-spotted salamander species (Ambystoma laterale and its hybrid complex) and the spring salamander Gyrinophilus porphyriticus are listed primarily because CT is at their range limit (Klemens 2000). The Jefferson salamander A. jeffersonianum is listed as it is especially susceptible to land fragmentation and habitat loss (Klemens 2000). The northern leopard frog is thought to have been more prevalent in the state at one time, but is sensitive to acidic environmental conditions (i.e. acid rain) and is now mostly found in areas dominated by limestone (Klemens 2000). Some of the other species, such as the green frog, bullfrog, and pickerel frog, dominate the landscape and can be found in nearly all types of wetlands, from early summer to mid-fall (Klemens 2000).

\section{MATERIALS AND METHODS}

\section{Study area}

Our study area in CT was covered by the Laurentide ice sheet during the last glacial maximum, creat- ing the post-glacial terrain encountered today (see Fig. 1). In general, this area is dominated by mixed deciduous-coniferous forests intermixed with lowland areas and developed landscapes. The study region includes 2 upland areas on the east and west sides of the state separated by the wide Central Valley of CT containing the Connecticut River and much human development. Sites were randomly selected for survey, but ultimately the surveyed sites were those where we had the landowner's permission or the site was on state-owned land. Sampled sites spanned a wide range of ecosystems and environmental settings, including forested to open canopy, urban to rural settings, overgrown to minimal emergent vegetation, streams and ponds of all sizes and hydroperiods (permanent and temporary), lakes, and terrestrial areas surrounding waterbodies.

\section{Sample collection}

\section{Contemporary survey}

Because CT and several of the focal species had never been surveyed for $B d$, our approach to data collection was purely opportunistic, based entirely on access to the site and the presence of accessible animals to swab. The goal of this survey was to gather as much baseline data from as wide a geographic and species range as possible, rather than to test various drivers of prevalence (e.g. host species, site type, seasonal differences). Much of the sampling occurred as part of a partnership with the CT Department of Energy and Environmental Protection, and surveys were integrated with their standard statewide monitoring programs. There was neither a specific pattern for how the state was surveyed nor was any site resampled.

From May to November 2010, field researchers used gear decontaminated between site visits (10\% bleach solution; Cashins et al. 2008). Amphibians were captured, either by hand, with a new pair of latex or nitrile gloves, or by dipnet. All available species and individuals at a site were targeted, regardless of age or sex, and swabbed according to standardized practices (see Hyatt et al. 2007): the captured animal was restrained and a wooden toothpick rubbed over its body, focusing on the limbs, feet, and drink patch (groin) for metamorphosed anurans, only the mouthparts for anuran larvae, or the entire body for caudates. These respective locations on the body have been found to increase the likelihood of detecting $B d$ zoospores in these taxa and age classes 
(Hyatt et al. 2007). The animals were returned to their site of capture. While cotton-tipped, wire swabs (e.g. Medical Wire \& Equipment MW 100-100) are a common collection tool, toothpicks have been used successfully in previous studies to collect $B d$ from amphibians (Retallick et al. 2006, Woodhams et al. 2006, Retallick \& Miera 2007, Hyman \& Collins 2012). Despite the popularity of wire swabs, there is no evidence demonstrating that wooden toothpicks are any better or worse at collecting $B d$. Toothpicks were placed into a $2 \mathrm{ml}$ screw cap tube containing $70 \%$ ethanol. Each sampling effort at a site concluded once all accessible animals were swabbed; there were no time limits imposed per sampling effort. In total, 916 individuals were sampled from 116 sites, and swabs were transported back to the lab and kept at room temperature until DNA extraction. All animals were captured and handled according to an approved protocol (no. 2009-11306) from the Institutional Animal Care and Use Committee of Yale University or the Connecticut General Statute 26-3.

\section{Preserved specimen survey}

Wood frog tadpoles ( $\mathrm{n}=239$ ) previously collected (and unused) for another study were screened for $B d$. These CT specimens, preserved in $70 \%$ ethanol, were collected in May 2007 from Berlin $(n=35)$, East Haven $(\mathrm{n}=28)$, Meriden $(\mathrm{n}=61)$, North Branford $(\mathrm{n}=$ $72)$, and Wallingford $(\mathrm{n}=43)$. Tissues taken from these tadpoles were half a mouthpart (cut down the sagittal plane) and, if available, 1 of each fore- and hindlimb. Tissues were excised using sterile equipment, including a new razor blade for each individual. All tissues were extracted and analyzed for $B d$ via quantitative PCR (qPCR; see below).

\section{DNA extraction and $q P C R$}

For the preserved amphibian tissues, DNA was extracted using the Gentra PureGene protocol (Qiagen). DNA from swabs was extracted according to Retallick et al. (2006) with a minor modification: we used $100 \mu$ l of PrepMan Ultra (Applied Biosystems) rather than $40 \mu \mathrm{l} . \quad B d$ DNA was detected via qPCR according to Boyle et al. (2004) and Garland et al. (2010). Briefly, $20 \mu$ reaction volumes consisted of $5 \mu \mathrm{l}$ of DNA template (diluted 1:10 for field swabs or full strength for preserved tadpoles), $10 \mu \mathrm{l}$ qPCR master mix (initially, TaqMan Universal No AmpErase, Applied Biosystems, then a final switch to SensiMix II Probe Low ROX, Bioline), $1 \mu$ of each primer (forward and reverse; $900 \mathrm{~nm}$ each), $2 \mu \mathrm{l}$ of probe $(250 \mathrm{~nm})$, and $1 \mu \mathrm{l}$ BSA (500 ng $\mu^{-1}$ ). Diluting DNA from swab samples and the addition of BSA helps to reduce inhibition in qPCR (Garland et al. 2010). The qPCR protocol was: $10 \mathrm{~min}$ activation at $95^{\circ} \mathrm{C}$ followed by 45 cycles of $15 \mathrm{~s}$ at $95^{\circ} \mathrm{C}$ and $60 \mathrm{~s}$ at $60^{\circ} \mathrm{C}$. qPCR assays included a negative control (molecular grade DNase-free water) and 3 dilutions (100, 10, or 1 zoospore per $20 \mu \mathrm{l}$ reaction) of a positive control standard ( $B d$ isolate JAM081). The protocol for preparing standard positive controls followed Boyle et al. (2004): zoospores were harvested by flooding the agar plate with DNase free water and pipetting the supernatant into $15 \mathrm{ml}$ tubes. Harvested zoospores were counted 4 times using a hemocytometer. All samples, including the controls, were run in triplicate. Presence of $B d$ in each sample was determined by successful amplification of the 146 base pair fragment within $B d$ 's ribosomal DNA (rDNA) (Boyle et al. 2004). Any sample in which at least 2 of the 3 wells (replicates) had successful amplification was deemed positive for $B d$. Any sample that reported only 1 positive well was rerun. Samples that had no amplification in all 3 wells were deemed negative for $B d$. The reported numbers of zoospores per swab have not been adjusted; the reported numbers of zoospores come from a $5 \mu$ aliquot from a 1:10 dilution of the original DNA extract, all in a $20 \mu \mathrm{l}$ reaction volume.

\section{Statistical analyses}

The qPCR assay detects $B d$ and through the use of standard positive control dilutions, it quantifies how much $B d$ is in every well, providing the mean number of zoospores from all replicates. In addition to the mean zoospore load per sample, data collected include: (1) host life stage, (2) host order, (3) host family, (4) host species, (5) host sex, (6) the presence/ absence of each taxonomic order at a site, (7) the presence/absence of each taxonomic family at a site, and (8) the presence/absence of each species at a site. Variables 1 to 5 represent individual-level variables and 6 to 8 represent site-level variables. We did not test for temporal patterns of $B d$ prevalence because every site was sampled once, leading to autocorrelation between site and date. All statistical tests and models were calculated using Minitab 16. Graphics were created in ESRI ArcMap v10 and Microsoft Excel 2007. 


\section{Analysis of infection probability}

Due to high degrees of colinearity, unbalanced sampling, over-representation of particular observations (i.e. species, sex), and insufficient degrees of freedom, there were no significant interactions among variables; therefore, variables were tested in individual univariate analyses of variance (ANOVAs) on the same response variable, $B d$-positive or -negative, using a Tukey-Kramer post hoc test. Following a significant univariate effect, binary logistic regression models were run to assess how the levels of each variable influenced the likelihood of $B d$ infection, using the binary outcome, $B d$-positive or -negative, as the response variable; interaction terms were not included. Binary logistic regressions set 1 level as the reference, meaning that comparisons within a predictor variable (e.g. host family) are only possible between the reference and another variable level, not between 2 non-reference variables. For example, when evaluating how the likelihood of infection changes within anuran families, comparisons can only be made between the reference value, bufonids, and either hylids or ranids, not between hylids and ranids. Non-significant variable levels were removed until the model achieved significance. In addition, we used Bonferroni tests to correct for multiple comparisons and to obtain an adjusted alpha level.

\section{Probability of carrying higher zoospore loads}

A series of general linear models were fit to the above individual-level predictor variables (1 to 5 ) to assess how each variable influenced the likelihood of an individual carrying more zoospores; no interac-

Table 1. Number of Batrachochytrium dendrobatidis $(B d)$-positive and negative swabs collected from Connecticut (CT), USA, amphibians in 2010. Data from 18 species are organized by species and age class. Values in bold font exclude data from the larval age class. Missing values indicate no samples taken. N: northern; Neg: negative for $B d$; Pos: positive for $B d$; Juv: juvenile; Meta: metamorph

\begin{tabular}{|c|c|c|c|c|c|c|c|c|c|}
\hline \multirow[t]{2}{*}{ Species } & \multicolumn{2}{|c|}{ Adult } & \multicolumn{2}{|c|}{ Juv/Meta } & \multicolumn{2}{|c|}{ Larva } & \multirow[b]{2}{*}{ Total } & \multicolumn{2}{|c|}{ Grand total } \\
\hline & Neg & Pos & Neg & Pos & Neg & Pos & & Proportion pos & $95 \% \mathrm{CI}$ \\
\hline \multirow[t]{2}{*}{ Frogs and toads } & 266 & 116 & 206 & 121 & 61 & 1 & 771 & 0.31 & $0.28-0.34$ \\
\hline & & & & & & & 709 & 0.33 & $0.30-0.37$ \\
\hline American toad & 2 & & 8 & 1 & & & 11 & 0.09 & $0.002-0.41$ \\
\hline \multirow[t]{2}{*}{ Bullfrog } & 28 & 26 & 38 & 5 & 8 & & 105 & 0.30 & $0.21-0.39$ \\
\hline & & & & & & & 97 & 0.32 & $0.21-0.39$ \\
\hline Fowler's toad & & & 9 & & & & 9 & 0 & $0-0.28$ \\
\hline \multirow[t]{2}{*}{ Green frog } & 188 & 78 & 93 & 93 & 10 & & 462 & 0.37 & $0.33-0.42$ \\
\hline & & & & & & & 452 & 0.38 & $0.33-0.42$ \\
\hline \multirow[t]{2}{*}{ Grey tree frog } & 1 & & 9 & & 2 & 1 & 13 & 0.08 & $0.002-0.36$ \\
\hline & & & & & & & 10 & $\mathbf{0}$ & $0-0.26$ \\
\hline N. leopard frog ${ }^{\mathrm{a}}$ & 11 & 6 & 4 & 3 & & & 24 & 0.38 & $0.19-0.59$ \\
\hline Pickerel frog & 13 & 6 & 35 & 17 & & & 71 & 0.32 & $0.22-0.45$ \\
\hline \multirow{2}{*}{ Rana spp. } & 3 & & 5 & & 40 & & 48 & 0 & $0-0.06$ \\
\hline & & & & & & & 8 & $\mathbf{0}$ & $0-0.31$ \\
\hline Spring peeper & 11 & & 2 & & & & 13 & 0 & $0-0.21$ \\
\hline \multirow[t]{2}{*}{ Wood frog } & 9 & & 3 & 2 & 1 & & 15 & 0.13 & $0.02-0.40$ \\
\hline & & & & & & & 14 & 0.14 & $0.01-0.43$ \\
\hline \multirow[t]{2}{*}{ Salamanders } & 68 & 18 & 49 & 5 & 5 & 0 & 145 & 0.16 & $0.10-0.23$ \\
\hline & & & & & & & 140 & 0.16 & $0.11-0.24$ \\
\hline Blue-spotted $^{\mathrm{a}}$ & 1 & & 3 & & & & 4 & 0 & $0-0.53$ \\
\hline Dusky & 7 & 4 & 2 & 1 & & & 14 & 0.36 & $0.13-0.65$ \\
\hline Four-toed & & 1 & 1 & & & & 2 & 0.50 & $0.02-0.99$ \\
\hline Marbled & 1 & & 3 & & & & 4 & 0 & $0-0.53$ \\
\hline N. two-lined & 14 & & 1 & 1 & & & 16 & 0.06 & $0.002-0.30$ \\
\hline Red-backed & 36 & 7 & 6 & & & & 49 & 0.14 & $0.06-0.27$ \\
\hline \multirow[t]{2}{*}{ Red-spotted newt } & 9 & 5 & 27 & 2 & 5 & & 48 & 0.15 & $0.06-0.28$ \\
\hline & & & & & & & 43 & 0.16 & $0.07-0.31$ \\
\hline Spotted & & & 6 & 1 & & & 7 & 0.14 & $0.004-0.58$ \\
\hline Spring $^{a}$ & & 1 & & & & & 1 & 1.0 & $0.05-1$ \\
\hline \multirow[t]{2}{*}{ Grand total } & 334 & 134 & 255 & 126 & 66 & 1 & 916 & 0.28 & $0.26-0.32$ \\
\hline & & & & & & & 849 & 0.31 & $0.28-0.34$ \\
\hline
\end{tabular}


tion terms were included in the models, nor did any model test more than 1 predictor variable at a time. The response variable, number of zoospores per swab (range 0.006 to 29420 zoospores), was logtransformed to meet model assumptions. As before, the larval stage was removed, and we corrected for multiple comparisons using Bonferroni tests. Lastly, differences in zoospore load between infected species were assessed using a 1-sided Student's $t$-test to specifically test whether a particular species carried more zoospores than another species.

\section{RESULTS}

We did not detect $B d$ in any of the larval wood frogs collected in 2007. From the 2010 contemporary sampling effort, 261 of all 916 individuals (a prevalence of 0.28 , with a $95 \%$ confidence interval of 0.26 to 0.32 ,), were found positive for $B d$ (Table 1). Of the 916 swabs, 67 were from pre-metamorphic individuals and of those, only 1 grey tree frog Hyla versicolor tadpole was found $B d$-positive. If the larval stage is not considered, the overall prevalence was $0.31(0.28$ to 0.34 ; Table 1 ). The majority, $50.4 \%$, of swabs were collected from green frogs (Table 1). $B d$ prevalence in 4 of the most often captured metamorphosed species, red-spotted newts Notophthalmus viridescens, red-backed salamanders Plethodon cinereus, bullfrogs, and green frogs, ranged from 0.14 to 0.38 (Table 1). Of the 260 swabs from infected postmetamorphs, 210 were measured quantitatively. The range in zoospore loads per swab was 0.006 to 29420 (Table 2). Four species were negative for $B d$ across all age classes: Fowler's toads Bufo fowleri, spring peepers Pseudacris crucifer, blue-spotted salamanders, and marbled salamanders Ambystoma opacum (Table 1). Three sampled species (blue-spotted salamanders, spring salamanders, and northern leopard frogs) are listed as species of conservation concern in CT (Table 1). Sample sizes were low for each of these listed species, but both spring salamanders and northern leopard frogs had at least 1 infected post-metamorphic individual. No captured animal showed any signs of infection or decrement in physical condition during the course of the survey.

In total we surveyed 116 sites in 2010 for $B d$ (Fig. 1, Table 3). Per site, the range in $B d$ prevalence was 0.0 to 1.0, and of any site with at least 1 infected individual, the lowest detected prevalence was 0.04 (0.005 to 0.13; Table 3). In infinitely large populations, sampling 30 individuals can detect, with $95 \%$ confidence, at least 1 infected individual if $B d$ is in $\leq 0.10$ of the population (Cannon \& Roe 1982). Therefore, prevalence of infection in the $75 B d$-positive sites was likely $\geq 0.10$ because we detected at least $1 B d$-positive animal in each of those sites (the number of sampled animals from each of those sites ranged from 1 to 53; Table 3 ). Of the 41 sites that had no $B d$-positive animals, the number of swabs collected ranged from 1 to 20 (Table 3). Collecting 1 or 20 swabs per site decreases detection probability to 9 and $85 \%$, respectively (Cannon \& Roe 1982); thus, given the sample sizes for the $B d$-negative sites, we can assert with far less certainty that $B d$ was prevalent in $\leq 0.10$ of each site's population.

\section{Infection prevalence and zoospore load}

Infection prevalence among the life stages varied significantly $\left(F_{2,913}=14.34, \mathrm{p}=0.000\right)$. All but 67 individuals sampled were post-metamorphic, and the infection prevalence of those larvae was very low (Table 1). Larvae were at least 26.48 times less likely to be infected than either other post-metamorphic life stage (Table 4). For all subsequent models, records with larvae were excluded, leaving 849 post-metamorphic individual records and 116 site records. Similarly, because there was a significant difference of infection prevalence between anurans and caudates $\left(F_{1,847}=16.17, \mathrm{p}=0.000\right.$;

Table 2. Measured $B d$ zoospore load per swab of only post-metamorphic age classes. Pos: no. of individuals tested positive for $B d_{i}$ N.: northern

\begin{tabular}{|lrcrrrr|}
\hline Species & Pos & Min & Max & Mean & Median & SD \\
\hline Frogs and toads & & & & & & \\
American toad & 1 & & & & 0.31 & \\
Bullfrog & 27 & 0.068 & 535.00 & 42.88 & 1.41 & 135.86 \\
Green frog & 152 & 0.026 & 29419.74 & 358.58 & 4.26 & 2536.75 \\
N. leopard frog & 8 & 0.085 & 10588.50 & 2210.70 & 108.34 & 3726.23 \\
Pickerel frog & 13 & 0.107 & 7087.83 & 651.24 & 86.77 & 1943.40 \\
Salamanders & & & & & & \\
Dusky & 4 & 0.037 & 131.70 & 33.07 & 0.27 & 65.75 \\
N. two-lined & 1 & & & & 33.48 & \\
Red-backed & 1 & & & & 0.97 & \\
Red-spotted newt & 3 & 0.006 & 6.23 & 2.75 & 2.01 & 3.18 \\
Total across all species & 210 & 0.006 & 29419.74 & 390.42 & 4.38 & 2342.56 \\
a Species of conservation concern in Connecticut & & & \\
\hline
\end{tabular}




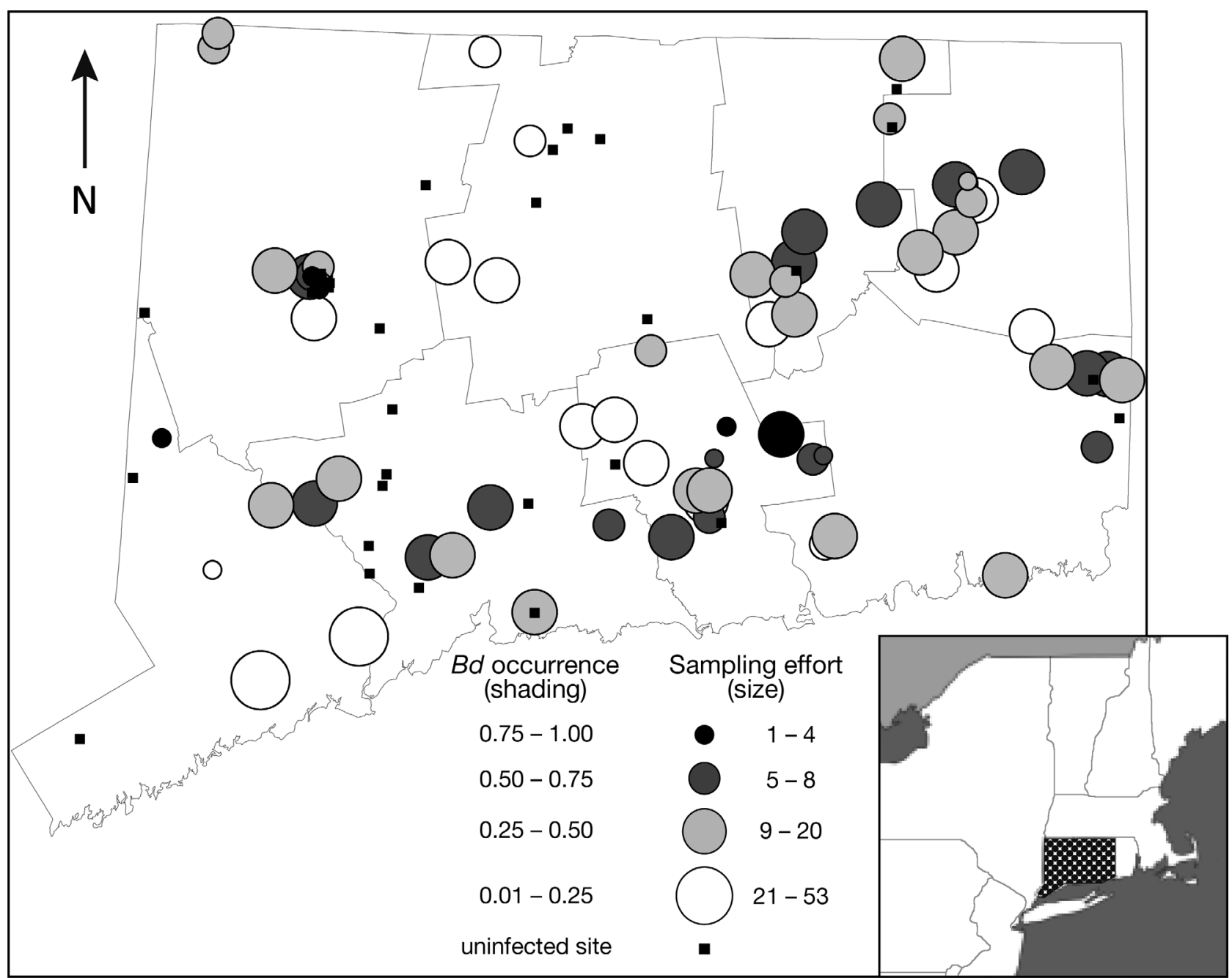

Fig. 1. Sampling locations of 99 field sites throughout Connecticut, USA (stippled area in inset). Sites without GPS coordinates were excluded (Batrachochytrium dendrobatidis $[B d]$-positive sites $\mathrm{n}=9 ; B d$-negative sites $\mathrm{n}=8$ ). Circle shading indicates percent $B d$-positive individuals per site and circle size indicates sampling effort (no. of individuals)

Table 4), all subsequent models were separated based on taxonomic order. Within caudates, there were no significant differences among family $\left(F_{2,137}\right.$ $=0.62, \mathrm{p}=0.541)$, species $\left(F_{8,131}=1.75, \mathrm{p}=0.094\right)$, life stage $\left(F_{1,138}=3.32, \mathrm{p}=0.071\right)$, or $\operatorname{sex}\left(F_{2,137}=\right.$ $.039, \mathrm{p}=0.677)$. Within anurans, there were significant differences among family $\left(F_{2,706}=10.26, \mathrm{p}=\right.$ $0.000)$, species $\left(F_{9,699}=3.38, \mathrm{p}=0.000\right)$, and sex $\left(F_{2,706}=7.56, \mathrm{p}=0.001\right)$. The differences among anuran species, however, were solely between the most sampled (and infected) species (green frogs, bullfrogs, northern leopard frogs, and pickerel frogs) and the species that were rarely sampled and had no detectable infections (Fowler's toad, grey tree frogs, spring peepers, and unidentified ranids). When these poorly sampled and $B d$-nega- tive species were removed from the model, the pattern disappeared $\left(F_{5,663}=1.62, \mathrm{p}=0.154\right)$; post hoc Student's $t$-tests also supported there being no significant differences among the $B d$-positive species. Prevalence among anuran life stages was not significantly different $\left(F_{1,707}=3.49, \mathrm{p}=0.062\right)$. Since 19 species from both orders were sampled, we investigated whether any species had a greater incidence of infection. $B d$ prevalence did vary among species $\left(F_{18,830}=3.23, \mathrm{p}=0.000\right)$, namely among green frogs, red-backed salamanders, and red-spotted newts $\left(F_{2,541}=8.97, \mathrm{p}=0.000\right)$. Following ANOVAs with significant effects, binary logistic regressions were run to determine how each level within the predictor variable compared in infection odds. The following increased the likelihood of 
infection: ranids versus bufonids or hylids, and the unknown/unrecorded sex or female anurans versus male anurans (Table 4). Among all species, of the 3 that varied in their infection odds, red-backed sala-

Table 3. Prevalence of $B d$ per site, grouped into prevalence bins, e.g. there were 11 sites where between 0.201 and 0.300 of swabbed individuals tested positive for $B d$. The number of individuals swabbed in any of these 11 sites ranged from 4 to 31

\begin{tabular}{|lcc|}
\hline Bd prevalence & No. sites & Sampling effort range \\
\hline 0 & 41 & $1-20$ \\
$0.001-0.10$ & 5 & $10-53$ \\
$0.101-0.20$ & 9 & $5-13$ \\
$0.201-0.30$ & 11 & $4-31$ \\
$0.301-0.40$ & 10 & $5-10$ \\
$0.401-0.50$ & 9 & $2-20$ \\
$0.501-0.60$ & 9 & $5-10$ \\
$0.601-0.70$ & 8 & $3-12$ \\
$0.701-0.80$ & 5 & $5-10$ \\
$0.801-0.90$ & 1 & 10 \\
$0.901-1.0$ & 8 & $1-2$ \\
Total & 116 & $1-53$ \\
\hline
\end{tabular}

manders and red-spotted newts were less likely to be infected than green frogs (Table 4). Bonferroni corrections did not alter model significance.

General linear models tested whether various predictors resulted in increased zoospore loads per individual (Table 5). As before, the larval stage was removed from all models. We found no differences in zoospore loads among orders or families ( $p>0.05)$; hence, models were run with all species together. Three models were significant: host life stage $\left(F_{1,208}=\right.$ $71.05, \mathrm{p}=0.000)$, host $\operatorname{sex}\left(F_{2,207}=21.40, \mathrm{p}=0.000\right)$, and host species $\left(F_{8,201}=2.80, \mathrm{p}=0.006\right.$; Table 6$)$. One-sided Student's $t$-tests confirmed that northern leopard frogs $(t=2.25, \mathrm{p}=0.027)$ and pickerel frogs $(t$ $=3.21, \mathrm{p}=0.002)$ carried more zoospores than bullfrogs. Bonferroni corrections did not alter model significance.

\section{Within-site infection prevalence}

$B d$ prevalence was dependent on which order(s) were present at a site $\left(F_{2,113}=3.40, \mathrm{p}=0.037\right)$; when

Table 4. Binary logistic regressions on the individual level with the response variable $B d$-positive or -negative. Larvae were removed from all but the first test. Only variables with significance $(\mathrm{p}<0.05)$ or close to significance were included. Comparisons within a predictor variable can only be made to the reference value. n: no. of records; juv: juvenile; F: female; U: unknown; Coeff: coefficient

\begin{tabular}{|c|c|c|c|c|c|c|}
\hline Model & Coeff & SE Coeff & $Z$ & $\mathrm{p}$ & Odds ratio & $95 \% \mathrm{CI}$ \\
\hline \multicolumn{7}{|l|}{ Three life stages, $n=916$} \\
\hline Constant (null model) & -4.19 & 1.01 & -4.16 & 0.000 & & \\
\hline Life stage, adult & 3.28 & 1.01 & 3.24 & 0.001 & 26.48 & $3.64-192.72$ \\
\hline Life stage, juv & 3.48 & 1.01 & 3.44 & 0.001 & 32.61 & $4.47-237.68$ \\
\hline \multicolumn{7}{|c|}{ Log-likelihood $=-527.262, G=40.195, \mathrm{df}=2, \mathrm{p}=0.000$} \\
\hline \multicolumn{7}{|l|}{ Host order, $\mathrm{n}=849$} \\
\hline Constant (null model) & -1.63 & 0.23 & -7.13 & 0.000 & & \\
\hline Host order, Anura & 0.94 & 0.24 & 3.88 & 0.000 & 2.55 & $1.59-4.10$ \\
\hline \multicolumn{7}{|c|}{ Log-likelihood $=-514.288, G=17.495, \mathrm{df}=1, \mathrm{p}=0.000$} \\
\hline \multicolumn{7}{|l|}{ Anuran families, $\mathrm{n}=709$} \\
\hline Constant (null model) & -2.94 & 1.03 & -2.87 & 0.000 & & \\
\hline Hylids & -10001.40 & 208514.00 & -0.05 & 0.962 & 0 & 0 \\
\hline Ranids & 2.34 & 1.03 & 2.28 & 0.023 & 10.43 & $1.39-78.38$ \\
\hline \multicolumn{7}{|c|}{ Log-likelihood $=-436.937, G=29.624, \mathrm{df}=2, \mathrm{p}=0.000$} \\
\hline \multicolumn{7}{|l|}{ Anuran sex, $\mathrm{n}=709$} \\
\hline Constant (null model) & -1.44 & 0.22 & -6.50 & 0.000 & & \\
\hline Sex, F & 0.90 & 0.28 & 3.25 & 0.001 & 2.47 & $1.43-4.25$ \\
\hline Sex, U & 0.90 & 0.24 & 3.67 & 0.000 & 2.45 & $1.52-3.96$ \\
\hline \multicolumn{7}{|c|}{ Log-likelihood $=-443.728, G=16.043, \mathrm{df}=2, \mathrm{p}=0.000$} \\
\hline \multicolumn{7}{|c|}{ Green frogs, red-backed salamanders, and red-spotted newts, $\mathrm{n}=544$} \\
\hline Constant (null model) & -0.50 & 0.10 & -5.12 & 0.000 & & \\
\hline Red-backed salamander & -1.29 & 0.42 & -3.09 & 0.002 & 0.27 & $0.12-0.62$ \\
\hline Red-spotted newt & -0.14 & 0.42 & -2.69 & 0.007 & 0.32 & $0.14-0.73$ \\
\hline Log-likelihood $=-338.98$ & $537, \mathrm{df}=2$ & 0.000 & & & & \\
\hline
\end{tabular}


both orders were found at a site, the site was more likely to be infected when compared to sites with just caudates (Table 6). However, after correcting for multiple comparisons using Bonferroni, the model was marginally significant $(\mathrm{p}=0.031$, adjusted alpha $=0.017$; Table 6 ). When testing whether the presence or absence of each of the families impacted $B d$ prevalence, only ranids increased its prevalence $\left(F_{1,114}=14.02, \mathrm{p}=0.000 ;\right.$ Table 5$)$. Specifically, when

Table 5. General linear models on the individual level with the response variable: $\log$-transformed number of $B d$ zoospores. Only infected individuals were included, and larvae were removed from all tests. Only variables with significance $(p<0.05)$ or close to significance were included. $n$ : no. of records; N.: northern; F: female; U: unknown; Coeff: coefficient

\begin{tabular}{|lrrrc|}
\hline Model & Coeff & SE Coeff & $t$ & $\mathrm{p}$ \\
\hline Two life stages, $\mathrm{n}=210$ & & & & \\
$\quad$ Constant (null model) & 0.67 & 0.08 & 8.85 & 0.000 \\
Life stage, adult & -0.64 & 0.08 & -8.43 & 0.000 \\
Host sex, $\mathrm{n}=210$ & & & & \\
Constant (null model) & 0.22 & 0.12 & 1.82 & 0.070 \\
Sex, F & -0.07 & 0.15 & -0.47 & 0.638 \\
Sex, U & 0.85 & 0.13 & 6.45 & 0.000 \\
Host species, n=210 & & & & \\
Constant (null model) & 0.55 & 0.27 & 2.09 & 0.038 \\
American toad & -1.06 & 1.11 & -0.96 & 0.340 \\
Bullfrog & -0.21 & 0.34 & -0.64 & 0.525 \\
Dusky salamander & -0.68 & 0.60 & -1.13 & 0.262 \\
N. leopard frog & 1.30 & 0.46 & 2.81 & 0.006 \\
N. two-lined salamander & 0.97 & 1.11 & 0.87 & 0.383 \\
Pickerel frog & 1.04 & 0.40 & 2.60 & 0.010 \\
Red-backed salamander & -0.57 & 1.11 & -0.51 & 0.609 \\
Red-spotted newt & -0.93 & 0.67 & -1.37 & 0.171 \\
\hline
\end{tabular}

green frogs were at a site, $B d$ was found in more hosts $\left(F_{1,114}=9.45, \mathrm{p}=0.003\right)$ than when green frogs were absent from sites (Table 5).

\section{DISCUSSION}

In our contemporary survey, 18 species were sampled at 116 sites, and $B d$ was found in a large proportion of all swabs (0.28). An infection prevalence of 0.28 , or 0.31 if only the post-metamorphs are considered, is very similar to the only other survey for $B d$ in the region. Longcore et al. (2007) found an infection prevalence of as high as 0.257 among the 74 screened northern leopard frogs. Given this result, we were not surprised to find an overall infection proportion of 0.28 across all species and age classes. We did not use an internal positive control in any $\mathrm{qPCR}$, which possibly leads to underestimations of $B d$ prevalence. However, as per Boyle et al. (2004) and Garland et al. (2010), DNA from our field swabs was diluted 1:10 and BSA added to every qPCR well to help reduce inhibition. Despite the possibility of underestimating $B d$ prevalence, our survey across CT represents one of the most intensive regional surveys for $B d$ and is the first for CT.

Table 6. Binary logistic regressions on the site level with the response variable: Bd-positive or -negative. Larvae were removed. Only variables with significance $(\mathrm{p}<0.05)$ or close to significance were included. Comparisons within a predictor variable can only be made to the reference value. n: no. of records; Coeff: coefficient

\begin{tabular}{|c|c|c|c|c|c|c|}
\hline Model & Coeff & SE Coeff & $Z$ & $\mathrm{p}$ & Odds ratio & $95 \% \mathrm{CI}$ \\
\hline \multicolumn{7}{|c|}{ Presence/absence of each or both orders, $n=116$} \\
\hline Constant (null model) & 1.73 & 0.63 & 2.77 & 0.006 & & \\
\hline Anurans, present & -1.18 & 0.67 & -1.78 & 0.076 & 0.31 & $0.08-1.13$ \\
\hline Caudates, present & -2.02 & 0.83 & -2.45 & 0.014 & 0.13 & $0.03-0.67$ \\
\hline Log-likelihood $=-71.865$ & $G=6.966$ & $\mathrm{df}=2$ & $\mathrm{p}=0.031$ & & & \\
\hline \multicolumn{7}{|c|}{ Presence/absence of ranids, $\mathrm{n}=116$} \\
\hline Constant (null model) & -0.85 & 0.49 & -1.74 & 0.082 & & \\
\hline Ranids, present & 1.79 & 0.54 & 3.32 & 0.001 & 5.96 & $2.08-17.12$ \\
\hline Log-likelihood $=-69.254$ & $G=12.189$ & $\mathrm{df}=1$ & $\mathrm{p}=0.000$ & & & \\
\hline \multicolumn{7}{|c|}{ Presence/absence of green frogs, $n=116$} \\
\hline Constant (null model) & -0.24 & 0.35 & -0.68 & 0.494 & & \\
\hline Green frogs, present & 1.24 & 0.43 & 2.91 & 0.004 & 3.45 & $1.50-7.96$ \\
\hline Log-likelihood $=-71.019$ & $G=8.660$ & $\mathrm{df}=1$ & $\mathrm{p}=0.003$ & & & \\
\hline
\end{tabular}


The most common ranid species at our sampling sites (bullfrogs, green frogs, northern leopard frogs, and pickerel frogs) had comparatively high levels of infection. It was not surprising that bullfrogs were in this group, as they have been shown in previous research to be a carrier, even an international carrier in the pet and food trade, of $B d$ (Daszak et al. 2004, Schloegel et al. 2009). Our data perhaps indicate that along with bullfrogs, these other ranids are also effective carriers of $B d$. Since these anuran species are equally likely to be infected, the most widely distributed species in this region (green frogs, bullfrogs, and pickerel frogs) could serve as sentinel species for monitoring programs concerned with $B d$ presence or absence across the state. These ranid species are relatively abundant and easy to find throughout the summer months, reasonably easy to swab given their larger body size, and they harbor $B d$. If monitoring programs wish to maximize their resources and simply screen for the presence of $B d$, the following factors could also be included in sampling schemes: focus on juveniles and adults (i.e. avoid larval stages), anurans, the female of any anuran species, and sites dominated by ranids (especially green frogs). To further investigate trends in zoospore loads, juveniles or northern leopard frogs or pickerel frogs should be targeted, as these carry greater zoospore loads than any other life stage or species. Reduced body size and an underdeveloped immune system have been hypothesized as reasons why juveniles carry greater zoospore loads than adults (Carey et al. 2006, Rachowicz et al. 2006, Pearl et al. 2009, Briggs et al. 2010).

Many zoospore loads were quite low ( $>0$ to 1 per swab), but the extracts were re-run and zoospore values were replicated, demonstrating that in this study, low zoospore loads are real and common. It is important to note, however, that metrics of zoospore load are associated with substantial variation related to sampling protocol. Different researchers swab differently - some swab more thoroughly or with greater pressure than those with a lighter hand or less skill (Retallick et al. 2006) - but there is probably a species, life stage, or even an individual host effect. Recent research found that zoospore load variation could not be explained solely by species, nor habitat, climate, or elevation; zoospore load may be entirely an individual host characteristic (Gründler et al. 2012). For example, it would not be surprising that a large, infected bullfrog would yield more zoospores than a small, infected red-backed salamander. In this case, body size could explain zoospore load differences, and it would not imply a greater or lesser 'infection intensity.' Alternatively, suppose the salamander was in an environment well suited to $B d$ growth $\left(17\right.$ to $25^{\circ} \mathrm{C}$, Piotrowski et al. 2004, Andre et al. 2008) versus a bullfrog that recently shed its skin and was sunning itself in temperatures at or beyond the thermal limit of $B d\left(>28^{\circ} \mathrm{C}\right.$, Piotrowski et al. 2004, Andre et al. 2008, Meyer et al. 2012). In this case, the resulting zoospore load comparison may be more similar; this would still not suggest any equality (or difference) in 'infection intensity.' Following a standard swabbing protocol (which was done here) in the field is valuable and necessary, but there are many factors outside the researcher's control that may influence measured zoospore loads. Therefore, we caution any interpretation of our tests evaluating how predictor variables likely increase zoospore load. Our model results, however, provide suggestive trends (e.g. adults carry fewer zoospores than juveniles), that require further research.

The low zoospore loads and the lack of $B d$-related dieoffs support the hypothesis that $B d$ is endemic in this region. In a related study system, Briggs et al. (2010) measured the infection dynamics for 5 yr at 3 sites with persistent $B d$ (endemic sites). The infection prevalence among the 3 sites ranged from 0.60 to 0.76 of all adult frogs, and the average zoospore load per post-metamorph was $4913 \pm 820$ zoospores. In another region similarly persisting with $B d$ and asymptomatic individuals, the average $B d$ prevalence was high ( 0.83 of post-metamorphic individuals), and the average $B d$ load ranged between 4 and 3861 zoospores $($ mean $=514$; Puschendorf et al. 2011). These studies report both a greater infection prevalence and higher average zoospore load than that found in CT. Of other surveys for $B d$ done elsewhere in the world $(95 \% \mathrm{CI}$ range reported here, except where noted), $0.20-0.36,0.04-0.14,0.96-$ $0.99,0-0.92$ (not CI), and $0.02-0.03$ of all sampled individuals were found to be $B d$-positive in Gabon, Peninsular Malaysia, Panama (El Cope), southeastern Brazil, and among 15 Asian countries, respectively (Lips et al. 2006, Bell et al. 2011, Savage et al. 2011, Swei et al. 2011, Gründler et al. 2012). While our reported prevalence does not mirror the upper limit measured during a dieoff in Panama (Lips et al. 2006) or levels measured at other persistent regions (California, Briggs et al. 2010; Australia, Puschendorf et al. 2011), a prevalence of 0.28 is moderate and within previously detected ranges. The presence of asymptomatic individuals with moderate prevalence and zoospore loads hints at some time having passed since the initial date of $B d$ emergence or arrival to the region, as zoospore load, prevalence, and mortality 
peak during the initial outbreak in naïve populations and subsequently taper off (Lips et al. 2006, Vredenburg et al. 2010, Puschendorf et al. 2011). For CT, at least 4 decades may have passed since these values likely peaked (Richards-Hrdlicka 2012).

While large-scale dieoffs are not currently documented in New England, it is unclear whether population declines in the past can be attributed to $B d$ infection. Three sampled species, northern leopard frogs, spring salamanders, and blue-spotted salamanders, are of conservation concern in $\mathrm{CT}$, largely because $\mathrm{CT}$ is near the range limit for these species. The single spring salamander sampled was infected, as were 9 of the 24 sampled northern leopard frogs; the 4 blue-spotted salamanders tested negative for $B d$. Although our sample sizes for these 3 species are small and we did not observe any clinical signs of infection, our preliminary data should be considered in a broader conservation context since this is the first time 2 of these species in this region were found to be $B d$-positive. Our work was not aimed at addressing whether $B d$ played a role in leading these species to a state of 'conservation concern.' However, given that $B d$ was not identified until the late 1990s (Berger et al. 1998, Longcore et al. 1999), it is possible that some of these species are also rare because of their susceptibility to chytridiomycosis. In the case of northern leopard frogs, past studies have highlighted the role of habitat loss and pond water acidification as possible causes of population decline in this region (Dunson et al. 1992, Simon et al. 2002, Brodkin et al. 2003, Gibbs et al. 2005). However, in light of our results, the potential for a combined effect of habitat stress and infection with $B d$ should not be overlooked.

Our sampling scheme was opportunistic, with an emphasis on gathering as much spatial and species coverage as possible. We did not resample any site or control for wetland type or dominant host species. Three inferences can be made from our collected samples: (1) green frogs are very abundant across the sampled region, (2) the sites sampled are those often preferred by green frogs and other ranids (i.e. few terrestrial environments were surveyed), and (3) although our sampling protocol was haphazard, we were able to detect $B d$ at 72 sites where $<30$ swabs (the minimum number to detect $B d$ in 0.10 of the population, see above) were collected. Perhaps we were lucky with these swabs, perhaps the true prevalence of $B d$ at those sites was very high, or perhaps our detection success is explained by the hosts from which those swabs came, i.e. primarily ranids. Our data do not allow for tests of whether there is a tem- poral pattern to $B d$ prevalence or whether species richness or abundance or certain wetland types (e.g. open versus closed canopy, semi-permanent, ephemeral) influence the prevalence of $B d$. However, our baseline data suggest that these are interesting hypotheses worthy of additional research. Future research into these putative trends will also inform whether there are hot spots of $B d$ infection and whether a single sampling event is sufficient to define the infection status of a given site.

None of the tadpoles collected in 2007 were positive for $B d$, suggesting that $B d$ was not in the host at the time of collection. The earliest published record of $B d$ in this region of the world is 1961 from SaintPierre-de-Wakefield, Quebec (Ouellet et al. 2005), Canada, and the earliest record of $B d$ in CT is 1968 (Richards-Hrdlicka 2012). Given that $B d$ has been in this area for decades and it has been successfully extracted and detected from other ethanol-preserved amphibian tissues (Soto-Azat et al. 2009, Voordouw et al. 2010), we are confident that our methods were sufficient to detect $B d$ if it was present in these samples. These tadpoles were quite small (Gosner stages 25 to 28; Gosner 1960), and half a mouthpart may not have captured a nascent infection at this early larval stage. To detect $B d$ in individuals, we recommend targeting larger animals and gathering a sample from a greater percentage of susceptible tissue, such as by employing epidermal swabs.

Our work adds to other documented cases where $B d$ prevalence can be widespread and infects many species, yet can be non-lethal to its hosts (Retallick et al. 2004, Briggs et al. 2010, Puschendorf et al. 2011). Not succumbing to lethal chytridiomycosis infections may be explained by the host's biology (including host defenses, life stage, sex), environmental conditions, or the pathogen itself (including pathogenesis), or some combination of these factors (Voyles et al. 2011). Recently, investigations have started to focus on the molecular basis of individual $B d$ isolates (Fisher et al. 2009, Rosenblum et al. 2010), and this line of research will be able to identify whether there are different strains of $B d$, whether they vary regionally, and whether some are more virulent than others. It may be that strains existing in $\mathrm{CT}$, or more broadly throughout New England, are less lethal than strains found in dieoff locations. Since the northeastern US is a suspected origin for the original emergence of $B d$ (James et al. 2009), this region should be monitored closely and future research planned to investigate whether $B d$ in the northeast is genetically distinct from strains in dieoff zones, perhaps warranting efforts to limit pathogen dispersal. Until then, we 
support recent efforts to prevent spreading $B d$ to new areas or even introducing novel strains to regions that are already infected with an undetermined strain (Phillott et al. 2010). Having baseline data about the geographic extent and species susceptibility to $B d$ infection in a region can be critically important in assessing population health, identifying concentrated infection zones, and providing useful guidelines to wildlife managers asked to prevent species declines. Understanding the dynamics of $B d$ through space and time could ultimately enable conservation managers to protect susceptible, endangered species in particular areas, or at the very least enforce decontamination of aquatic equipment between and within $B d$ hot spots.

Acknowledgements. This work was supported by the Yale Institute for Biospheric Studies (YIBS) Molecular Systematics and Conservation Genetics Laboratory, a YIBS Center for Field Ecology grant, and by the US Environmental Protection Agency's Science to Achieve Research Fellowship. White Memorial Conservation Center and Foundation, the Connecticut Audubon Society, and the CT Department of Energy and Environmental Protection (funded by a State Wildlife Grant) were strong supporters, providing us with numerous samples. We thank E. B. Rosenblum and S. Joneson for preparing and supplying culture material, and S. Attwood and M. Correa for laboratory assistance.

\section{LITERATURE CITED}

Andre SE, Parker J, Briggs CJ (2008) Effect of temperature on host response to Batrachochytrium dendrobatidis infection in the mountain yellow-legged frog (Rana muscosa). J Wildl Dis 44:716-720

Bell RC, Garcia AVG, Stuart BL, Zamudio KR (2011) High prevalence of the amphibian chytrid pathogen in Gabon. EcoHealth 8:116-120

Berger L, Speare R, Daszak P, Green DE and others (1998) Chytridiomycosis causes amphibian mortality associated with population declines in the rain forests of Australia and Central America. Proc Natl Acad Sci USA 95: 9031-9036

Bielby J, Bovero S, Sotgiu G, Tessa G and others (2009) Fatal chytridiomycosis in the Tyrrhenian painted frog. EcoHealth 6:27-32

Bosch J, Martínez-Solano I, García-París M (2001) Evidence of a chytrid fungus infection involved in the decline of the common midwife toad (Alytes obstetricans) in protected areas of central Spain. Biol Conserv 97:331-337

- Boyle DG, Boyle DB, Olsen V, Morgan JAT, Hyatt AD (2004) Rapid quantitative detection of chytridiomycosis (Batrachochytrium dendrobatidis) in amphibian samples using real-time Taqman PCR assay. Dis Aquat Org 60:141-148

Briggs CJ, Knapp RA, Vredenburg VT (2010) Enzootic and epizootic dynamics of the chytrid fungal pathogen of amphibians. Proc Natl Acad Sci USA 107:9695-9700

Brodkin M, Vatnick I, Simon M, Hopey H, Butler Holston K, Leonard M (2003) Effects of acid stress in adult Rana pipiens. J Exp Zool A Comp Exp Biol 298:16-22
Cannon RM, Roe RT (1982) Livestock disease surveys: a field manual for veterinarians. Australian Government Publishing Service, Canberra

> Carey C, Bruzgul JE, Livo LJ, Walling ML and others (2006) Experimental exposures of boreal toads (Bufo boreas) to a pathogenic chytrid fungus (Batrachochytrium dendrobatidis). EcoHealth 3:5-21

Cashins SD, Skerratt LF, Alford RA (2008) Sodium hypochlorite denatures the DNA of the amphibian chytrid fungus Batrachochytrium dendrobatidis. Dis Aquat Org 80: 63-67

Daszak P, Strieby A, Cunningham AA, Longcore JE, Brown CC, Porter D (2004) Experimental evidence that the bullfrog (Rana catesbeiana) is a potential carrier of chytridiomycosis, an emerging fungal disease of amphibians. Herpetol J 14:201-207

> Dunson W, Wyman R, Corbett E (1992) A symposium on amphibian declines and habitat acidification. J Herpetol 26:349-352

> Fisher MC, Bosch J, Yin Z, Stead DA and others (2009) Proteomic and phenotypic profiling of the amphibian pathogen Batrachochytrium dendrobatidis shows that genotype is linked to virulence. Mol Ecol 18:415-429

Gaertner JP, Forstner MRJ, O'Donnell L, Hahn D (2009) Detection of Batrachochytrium dendrobatidis in endemic salamander species from central Texas. EcoHealth 6: 20-26

> Garland S, Baker A, Phillott AD, Skerratt LF (2010) BSA reduces inhibition in a TaqMan ${ }^{\circledR}$ assay for the detection of Batrachochytrium dendrobatidis. Dis Aquat Org 92: 113-116

> Gibbs J, Whiteleather K, Schueler F (2005) Changes in frog and toad populations over 30 years in New York State. Ecol Appl 15:1148-1157

Gosner KL (1960) A simplified table for staging anuran embryos and larvae with notes on identification. Herpetologica 16:183-190

> Gründler MC, Toledo LF, Parra-Olea G, Haddad CFB and others (2012) Interaction between breeding habitat and elevation affects prevalence but not infection intensity of Batrachochytrium dendrobatidis in Brazilian anuran assemblages. Dis Aquat Org 97:173-184

> Hyatt AD, Boyle DG, Olsen V, Boyle DB and others (2007) Diagnostic assays and sampling protocols for the detection of Batrachochytrium dendrobatidis. Dis Aquat Org 73:175-192

> Hyman OJ, Collins JP (2012) Evaluation of a filtration-based method for detecting Batrachochytrium dendrobatidis in natural bodies of water. Dis Aquat Org 97:185-195

> James TY, Litvintseva AP, Vilgalys R, Morgan JAT and others (2009) Rapid global expansion of the fungal disease chytridiomycosis into declining and healthy amphibian populations. PLoS Pathog 5:e1000458

Klemens MW (2000) Amphibians and reptiles in Connecticut: a checklist with notes on status, identification, and distribution. Book 32. Connecticut Department of Environmental Protection, Hartford, CT

> Lips KR, Brem F, Brenes R, Reeve JD and others (2006) Emerging infectious disease and the loss of biodiversity in a Neotropical amphibian community. Proc Natl Acad Sci USA 103:3165-3170

- Longcore JE, Pessier AP, Nichols DK (1999) Batrachochytrium dendrobatidis gen. et sp. nov. a chytrid pathogenic to amphibians. Mycologia 91:219-227

> Longcore JR, Longcore JE, Pessier AP, Halteman WA (2007) 
Chytridiomycosis widespread in anurans of northeastern United States. J Wildl Manag 71:435-444

Meyer EA, Cramp RL, Bernal MH, Franklin CE (2012) Changes in cutaneous microbial abundance with sloughing: possible implications for infection and disease in amphibians. Dis Aquat Org 101:235-242

Murphy PJ, St-Hilaire S, Bruer S, Corn PS, Peterson CR (2009) Distribution and pathogenicity of Batrachochytrium dendrobatidis in boreal toads from the Grand Teton area of western Wyoming. EcoHealth 6: $109-120$

> Ouellet M, Mikaelian I, Pauli BD, Rodrigue J, Green DM (2005) Historical evidence of widespread chytrid infection in North American populations. Conserv Biol 19: 1431-1440

Pearl CA, Bowerman J, Adams MJ, Chelgren ND (2009) Widespread occurrence of the chytrid fungus Batrachochytrium dendrobatidis on Oregon spotted frogs (Rana pretiosa). EcoHealth 6:209-218

Phillott AD, Speare R, Hines H, Skerratt LF and others (2010) Minimising exposure of amphibians to pathogens during field studies. Dis Aquat Org 92:175-185

> Piotrowski JS, Annis SL, Longcore JE (2004) Physiology of Batrachochytrium dendrobatidis, a chytrid pathogen of amphibians. Mycologia 96:9-15

Puschendorf R, Hoskin CJ, Cashins SD, McDonald K, Skerratt LF, Vanderwal J, Alford RA (2011) Environmental refuge from disease-driven amphibian extinction. Conserv Biol 25:956-964

Rachowicz LJ, Roland AK, Morgan JAT, Stice MJ, Vredenburg VT, Parker JM, Briggs CJ (2006) Emerging infectious disease as a proximate cause of amphibian mass mortality. Ecology 87:1671-1683

Retallick RWR, Miera V (2007) Strain differences in the amphibian chytrid Batrachochytrium dendrobatidis and non-permanent, sub-lethal effects of infection. Dis Aquat Org 75:201-207

Retallick RWR, McCallum H, Speare R (2004) Endemic infection of the amphibian chytrid fungus in a frog community post-decline. PLoS Biol 2:e351

Retallick RWR, Miera V, Richards KL, Field KJ, Collins JP (2006) A non-lethal technique for detecting the chytrid fungus Batrachochytrium dendrobatidis on tadpoles. Dis Aquat Org 72:77-85

Richards-Hrdlicka KL (2012) Extracting the amphibian chytrid fungus from formalin-fixed specimens. Methods Ecol Evol 3:842-849, doi:10.1111/j.2041-1210X.2012. 00228.x

Rosenblum EB, Fisher MC, James TY, Stajich JE, Longcore JE, Gentry LR, Poorten TJ (2010) A molecular perspec-

Editorial responsibility: Alex Hyatt, Geelong, Victoria, Australia tive: biology of the emerging pathogen Batrachochytrium dendrobatidis. Dis Aquat Org 92:131-147

Savage AE, Grismer LL, Anuar S, Onn CK and others (2011) First record of Batrachochytrium dendrobatidis infecting four frog families from peninsular Malaysia. EcoHealth 8: 121-128

Schloegel LM, Picco AM, Kilpatrick AM, Davies AJ, Hyatt AD, Daszak P (2009) Magnitude of the US trade in amphibians and presence of Batrachochytrium dendrobatidis and ranavirus infection in imported North American bullfrogs (Rana catesbeiana). Biol Conserv 142: 1420-1426

Simon M, Vatnick I, Hopey H, Butler K and others (2002) Effects of acid exposure on natural resistance and mortality of adult Rana pipiens. J Herpetol 36:697-699

Soto-Azat C, Clarke BT, Fisher MC, Walker SF, Cunningham AA (2009) Non-invasive sampling methods for the detection of Batrachochytrium dendrobatidis in archived amphibians. Dis Aquat Org 84:163-166

Stuart SN, Chanson JS, Cox NA, Young BE, Rodrigues ASL, Fischman DL, Waller RW (2004) Status and trends of amphibian declines and extinctions worldwide. Science 306:1783-1786

Swei A, Rowley JJL, Rödder D, Diesmos MLL and others (2011) Is chytridiomycosis an emerging infectious disease in Asia? PLoS ONE 6:e23179

- Voordouw MJ, Adama D, Houston B, Govindarajulu P, Robinson J (2010) Prevalence of the pathogenic chytrid fungus, Batrachochytrium dendrobatidis, in an endangered population of northern leopard frogs, Rana pipiens. BMC Ecol 10:6

> Voyles J, Rosenblum EB, Berger L (2011) Interactions between Batrachochytrium dendrobatidis and its amphibian hosts: a review of pathogenesis and immunity. Microbes Infect 13:25-32

> Vredenburg VT, Knapp RA, Tunstall TS, Briggs CJ (2010) Dynamics of an emerging disease drive large-scale amphibian population extinctions. Proc Natl Acad Sci USA 107:9689-9694

> Wake DB, Vredenburg VT (2008) Are we in the midst of the sixth mass extinction? A view from the world of amphibians. Proc Natl Acad Sci USA 105:11466-11473

> Woodhams DC, Voyles J, Lips KR, Carey C, Rollins-Smith LA (2006) Predicted disease susceptibility in a Panamanian amphibian assemblage based on skin peptide defenses. J Wildl Dis 42:207-218

Woodhams DC, Kilburn VL, Reinert LK, Voyles J and others (2008) Chytridiomycosis and amphibian population declines continue to spread eastward in Panama. EcoHealth 5:268-274

Submitted: October 17, 2011; Accepted: October 1, 2012 Proofs received from author(s): February 13, 2013 